\title{
Effect of Equivalence Ratio on Composition and performance of Biogas and Gasoline Exhaust from Spark Ignition Engine by Mathematical Modeling
}

\author{
Paramust Juntarakod ${ }^{a}$ \\ Department of Mechatronic Engineering, Faculty of Engineering. Rajamangala University of Technology Isan, \\ Khonkaen Campus 150 Srichan Road, NaiMuang, Muang, Khonkaen, 40000, Thailand
}

\begin{abstract}
This paper presents the numerical computationnal of pressure, temperature and exhaust characteristics of spark ignition engine with biogas as fuel. The solution of non-linear combustion equation systems have been computed, that based on a quasi-one-dimensional engine model, high order iteration method with the equilibrium constants method. Computer program was used to calculate the mole fractions of 10 combustion products when biogas and gasoline fuel are burnt along with variable equivalence ratios. In cylinder chamber model is based on the classical two-zone approach, wherein parameters like heat transfer from the cylinder, blow by energy loss and heat release rate are also considered and calculated. Biogas is defined as fuel produced from using anaerobic digestion of biodegradable or waste materials and the constituents are $\mathrm{C}_{5} \mathrm{H}_{7} \mathrm{O}_{2} \mathrm{~N}, \mathrm{CH}_{4}, \mathrm{CO}_{2} \mathrm{~N}_{2} \mathrm{H}_{2} \mathrm{O}$ of biogas and $\mathrm{C}_{7} \mathrm{H} 1_{7}$ of gosoline. Which general fuel model is specified by way of its $\mathrm{C}_{\mathrm{a}} \mathrm{H}_{\mathrm{b}} \mathrm{O}_{c} \mathrm{~N}_{d}$ values. The curve-fitted coefficients of energy were then employed to simulate air and fuels data along with frozen composition and practical chemical equilibrium routines from Gill data. The calculated data were used to plot the various pressure and temperature with the crank angle of each step of four stroke engine cycle and combustion products versus equivalence ratio. All results were compared with gasoline as reference fuel in the spark ignition engine according to the same numerical method.
\end{abstract}

\section{Introduction}

In policy of Thailand, under the responsibility of Energy Policy and Planning Office (EPPO) and Department of Alternative Energy Development and Efficiency (DEDE), Thailand, they have proven to be a great success. Therefore, on determing that within 2021, 600 megawatt (MW) of electricity, 1,000 ktoe of heat should be generated from biogas and Excluding Elephant grass 3,000 megawatt (MW), Tawarath [1]. In academic or research, produced biogas in anaerobic digestion plants is primarily composed of methane $\left(\mathrm{CH}_{4}\right)$, carbon dioxide $\left(\mathrm{CO}_{2}\right)$, nitrogen $\left(\mathrm{N}_{2}\right)$ with smaller amounts of hydrogen sulfide $\left(\mathrm{H}_{2} \mathrm{~S}\right)$, ammonia $\left(\mathrm{NH}_{3}\right)$ and saturated with $\left(\mathrm{H}_{2} \mathrm{O}\right)$ water vapor. Most of the researches in biogas fuel on spark ignition engine were focused on experimental study for finding performance and emissions. For the value of biogas parameters for potential energy researches, the researches were conducted with five gas compositions; with $\mathrm{CH}_{4}=55-65$ (Vol. \%), $\mathrm{CO}_{2}=30-35$ (Vol. \%) and $\mathrm{N}_{2}=5$ (Vol. \%) respectively. In the present study, biogas was produced by anaerobic digestion of

\footnotetext{
${ }^{\mathrm{a}}$ Corresponding author : paramust_kmitnb@hotmail.com
} 
biodegradable materials, in this present used Buswell equation $\mathrm{C}_{5} \mathrm{H}_{7} \mathrm{O}_{2} \mathrm{~N}$ such as $53 \%\left(\mathrm{Vol}\right.$. \%) of $\mathrm{CH}_{4}$ and $47 \%$ (Vol. \%) of $\mathrm{CO}_{2}$, $\mathrm{LHV}$ is $19.1 \mathrm{MJ} / \mathrm{kg}$, [2].

In experiments using simulated biogas by Crookes, Sáawomir [3, 4 and 5] to find combustion products, he used the assumption that the engine parameters have the compression ratios from 11$13: 1$, they found the suitable operation without knocking by using the constant equivalence ratio of 0.8 and the variation of combustion products. In their case of a biogas fuelled engine simulation, the compression ratios that can be employed considerably higher than normal engine and the $\mathrm{CO}_{2}$ present help to suppress knocking. However, at high compression ratio, it was found to increase the $\mathrm{HC}$ and $\mathrm{NO}_{\mathrm{x}}$ levels, but reducing $\mathrm{N}_{2}$ and $\mathrm{CO}$ was found to be beneficial in lowering $\mathrm{NO}_{\mathrm{x}}$. In the present study, an effort is made by developing a new combustion mathematical model to simulate exhaust characteristics in biogas fuels by variation of equivalence ratio. The methods based on thermodynamic and equilibrium properties are constants, computer program using MATLAB which has been developed for the biogas-gasoline fuels to calculate the mole fractions of the emission gases by applying from Buttsworth [6]. Equilibrium constant method is based on thermodynamic measurements and empirical calculations [7, 8 and 9]. It is very accurate and precise in solving most of combustion and chemical kinetics problems. Some thermodynamic data for elements, combustion products and many pollutants are available in the new compilation published by Grill [7]. All results were compared by gasoline as fuel according to the same calculation method for all cases.

\section{Description of the mathematical model}

\subsection{Spark Ignition Engine model}

Mathematical model was applicable in any types of fuels provided the fuel induction technique was used or in other words the carburetion system with the used first law of thermodynamics, and this model was described as following equations Ferguson [8], Figure. 1. This model predicted the fuel inducted through the air inlet and serves as an alternative fuel (assumed biogas) to combust with fresh air as function of crank angle $\left({ }^{\circ} \theta\right)$ and thermo-fluids parameters. The mathematical models is to predict the temperature, pressure and engine performance by step by step of compression stroke, combustion stroke and expansion stroke, respectively, Mathematical model can be define as,

$$
\begin{aligned}
& \frac{d P}{d \theta}=\frac{A+B+C}{D+E} \\
& \frac{d T_{b}}{d \theta}=\frac{h \pi b^{2} / 2+4 v / b x_{b}^{1 / 2} \Delta T}{-v m c p b^{X}}+\frac{v_{b}}{c_{P b}}\left(\frac{\partial \ln v_{b}}{\partial \ln T_{b}}\right)\left(\frac{d P}{d \theta}\right) \\
& \frac{d T_{u}}{d \theta}=\frac{-h\left(\frac{\pi b^{2}}{2}+\frac{4 v}{b}\right) 1-x_{b}^{1 / 2} T_{u}-T_{w}}{v m c p b 1-x_{b}}+\frac{v_{u}}{c_{P b}}\left(\frac{\partial \ln v_{u}}{\partial \ln T_{u}}\right)\left(\frac{d P}{d \theta}\right)
\end{aligned}
$$

Where, the variation team in eq (1) A, B, C, D and E reference base on Ferguson [8].

\subsection{Assumption of the Carburetor model}

The control volume selected to analyze the flow in the mixing chamber is shown in the left hand section of Figure. 1. In the analysis, the following assumptions were made,

1) The inner wall of the carburetor is adiabatic and Friction loss is negligible.

2) The primary stream and secondary stream have the same static pressure at the entrance of the mixing chamber, $P_{p(\text { air })}=P_{s(\text { fuel })}=P$.

Both primary stream (air) and secondary stream (biogas fuel) can be considered as perfect gases with constant specific heat ratio $\gamma$. So, $m=m_{p(A i r)}+m_{s(f u e l)}$. Using the definition of critical condition, it can be shown fig. (1) that, 


$$
\begin{aligned}
& m_{p}=\frac{P_{P 0} A_{t}}{\sqrt{T_{0}}}=\sqrt{\frac{\gamma_{P}}{R_{P}}}\left(\frac{2}{\gamma_{P}+1}\right)^{\frac{\gamma_{P}+1}{\gamma_{P}-1}} \\
& m_{s}=\frac{P_{s 0} A_{s}}{\sqrt{T_{0}}}=\sqrt{\frac{\gamma_{s}}{R_{S}}}\left(\frac{2}{\gamma_{s}+1}\right)^{\frac{\gamma_{s}+1}{\gamma_{s}-1}}
\end{aligned}
$$

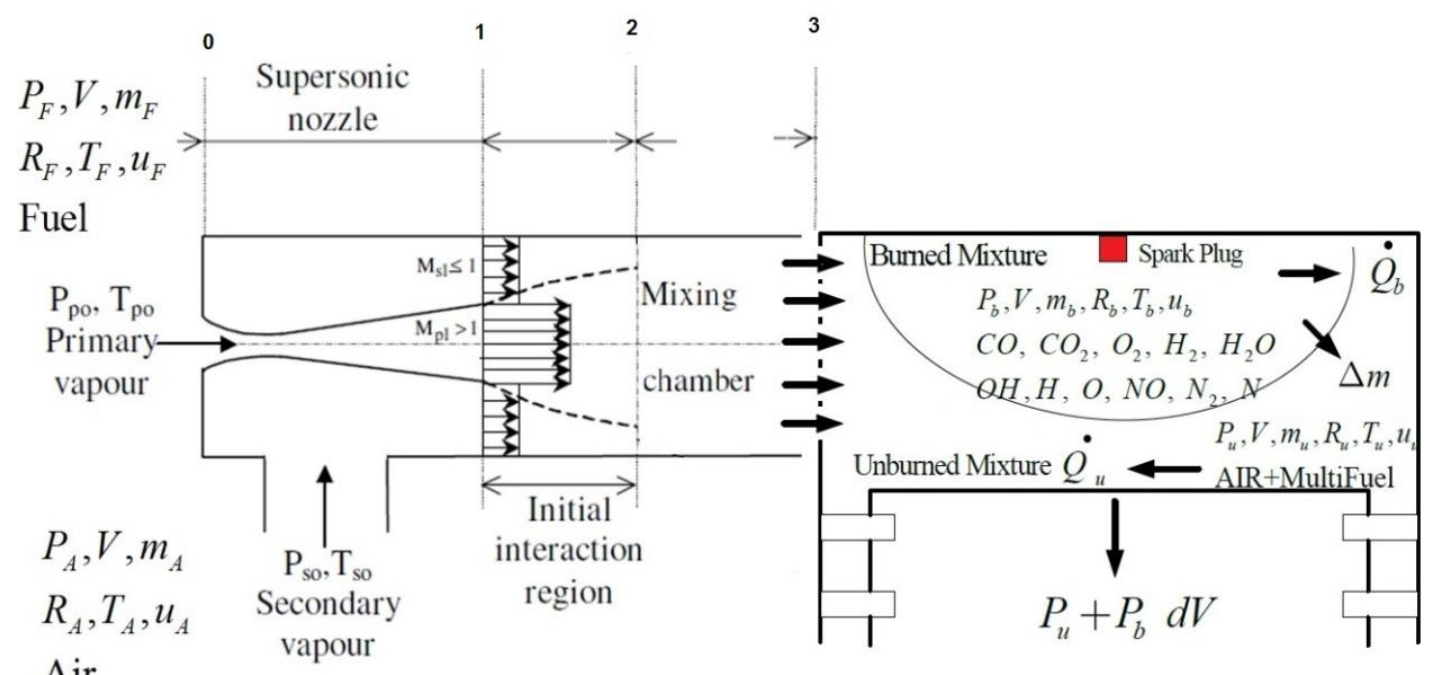

Air

Figure 1. Definition of fresh air, fuel intake (Carburetor model), SIE by Mathematical Modeling

\subsection{Practical of combustion and chemical equilibrium}

Basis of the equilibrium combustion products with fuel-air mixture model is a solution to the atom balance equations from the chemical reaction equation of fuel and air forming. This mixture equation is given in eq (6) for the condition of equivalence ratio $(\phi<3)$. This process based on conservation of mass that was modified form Buttsworth [6] and Ferguson [8], where the following equation represents the chemical reaction with the relevant species involved which was added gasoline supplied as given below,

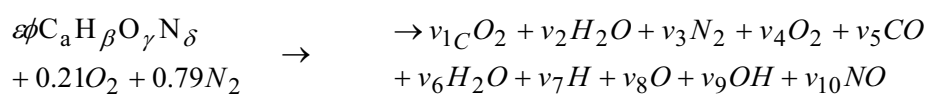

Where, $\varepsilon=4,(4 \alpha+\beta)$ and biogas, $\mathrm{C}_{5} \mathrm{H}_{7} \mathrm{O}_{2} \mathrm{~N}$ [2] , gasoline, $\mathrm{C}_{7} \mathrm{H}_{17}$ [8].

The method for solving of non-linear equation system, in the High order iteration Method was selected to solve in eq (6) with equilibrium constants method of biogas and gasoline fuels, which were summarized in eqs. (7) - (11). The many non-linear equations are available in the free compilation published by Paramust [10].

$$
\begin{aligned}
& f_{i}\left(y_{3}, y_{4}, y_{5} y_{6}\right)=0 \quad j=1,2,3,4 \\
& f_{1}\left(y_{3}, y_{4}, y_{5} y_{6}\right)=c_{1} y_{5} y_{4}^{1 / 2}+c_{2} y_{4} y_{6}^{1 / 2} y_{6}+y_{3}+y_{4}+y_{5}+y_{6}+c_{4} y_{6}^{1 / 2}+y_{5} y_{4}^{1 / 2}+c_{7} y_{4}^{1 / 2} y_{3}^{1 / 2}+c_{6} y_{3}^{1 / 2}-1 \\
& f_{2}\left(y_{3}, y_{4}, y_{5} y_{6}\right)=2\left(c_{2} y_{4}^{1 / 2} y_{6}\right)+2 c_{6}+c_{4} y_{6}^{1 / 2}+c_{3} y_{4}^{1 / 2} y_{6}^{1 / 2}-d_{1}\left(c_{1} y_{5} y_{4}^{1 / 2}+y_{5}\right) \\
& f_{3}\left(y_{3}, y_{4}, y_{5} y_{6}\right)=2\left(c_{1} y_{5} y_{4}^{1 / 2}\right)+c_{2} y_{6}^{1 / 2} y_{6}+2 y_{4}+y_{5}+c_{5} y_{4}^{1 / 2}+c_{3} y_{4}^{1 / 2} y_{6}^{1 / 2}+c_{7} y_{4}^{1 / 2} y_{3}^{1 / 2}-d_{2}\left(c_{1} y_{5} y_{4}^{1 / 2}-y_{5}\right) \\
& f_{4}\left(y_{3}, y_{4}, y_{5} y_{6}\right)=2\left(c_{2} y_{4}^{1 / 2} y_{6}\right)+c_{7} y_{4}^{1 / 2} y_{3}^{1 / 2}+c_{6} y_{3}^{1 / 2}-d_{3}\left(c_{1} y_{5} y_{4}^{1 / 2}+y_{5}\right)
\end{aligned}
$$

\section{Results and discussions}


The simulation was developed under no-load operating conditions compared gasoline and biogas fuel . The pressure change from compression stroke to expansion was clearly shown in Fig. 2 (left). The unburned and burned gas temperature was shown in Fig. 2 (right). Both pressure and temperature history was very useful parameter to determine the performance (work output of engine) of the engine cycle. The unburned gas temperature was usually referred to the residual gas whereby the burned gas temperature was referring to the gaseous burned during the combustion. This fig can show the average work cycles of the cylinder engine during the compression to the expansion stroke. Fig. 3 is the effect of equivalence ratio on composition of Biogas and Gasoline, it shows the average emissions of the burned gas during the combustion where using the varied equivalence ratio between 0.5 to 2.0 by high iteration method. This is numerical results and not the experimental result. An assumption on engine specification to be used in the calculation is shown in Table 1. The two versions of the simulation were used to compute engine performance (area of pressure-volume diagram) for the above conditions.

Table 1. The engine specifications for computing and outputs[10]

\begin{tabular}{|l|l|}
\hline \multicolumn{1}{|c|}{ Input parameters } & \multicolumn{1}{|c|}{ Values } \\
\hline Bore $(\mathrm{m}) /$ Stroke $(\mathrm{m}) /$ Stroke per 2 (rod Length) & $0.068 / 0.0540 .25$ \\
\hline Compression ratio/ Press $(\mathrm{kPa}) / \mathrm{Temp}\left({ }^{\circ} \mathrm{K}\right)$ & $8.5 / 100 / 350$ \\
\hline Start and Finish of Combustion process & $-35^{\circ} \theta$ BTDC and $40^{\circ} \theta$ ATDC \\
\hline Engine speed (RPM) & 1,000 \\
\hline \multicolumn{1}{|c|}{ Computing } & \multicolumn{1}{c|}{ Output } \\
\hline Biogas (B) $\mathrm{C}_{5} \mathrm{H}_{7} \mathrm{O}_{2} \mathrm{~N}$, Gasoline $(\mathrm{G}) \mathrm{C}_{7} H_{17}$ & Press and Temp vs. crank angle, (Figure.2) \\
\hline Biogas (B) $\mathrm{C}_{5} \mathrm{H}_{7} \mathrm{O}_{2} \mathrm{~N}$, Gasoline $(\mathrm{G}) C_{7} H_{17}$ & Mole fraction vs. equivalence ratio (Figure. 3) \\
\hline
\end{tabular}
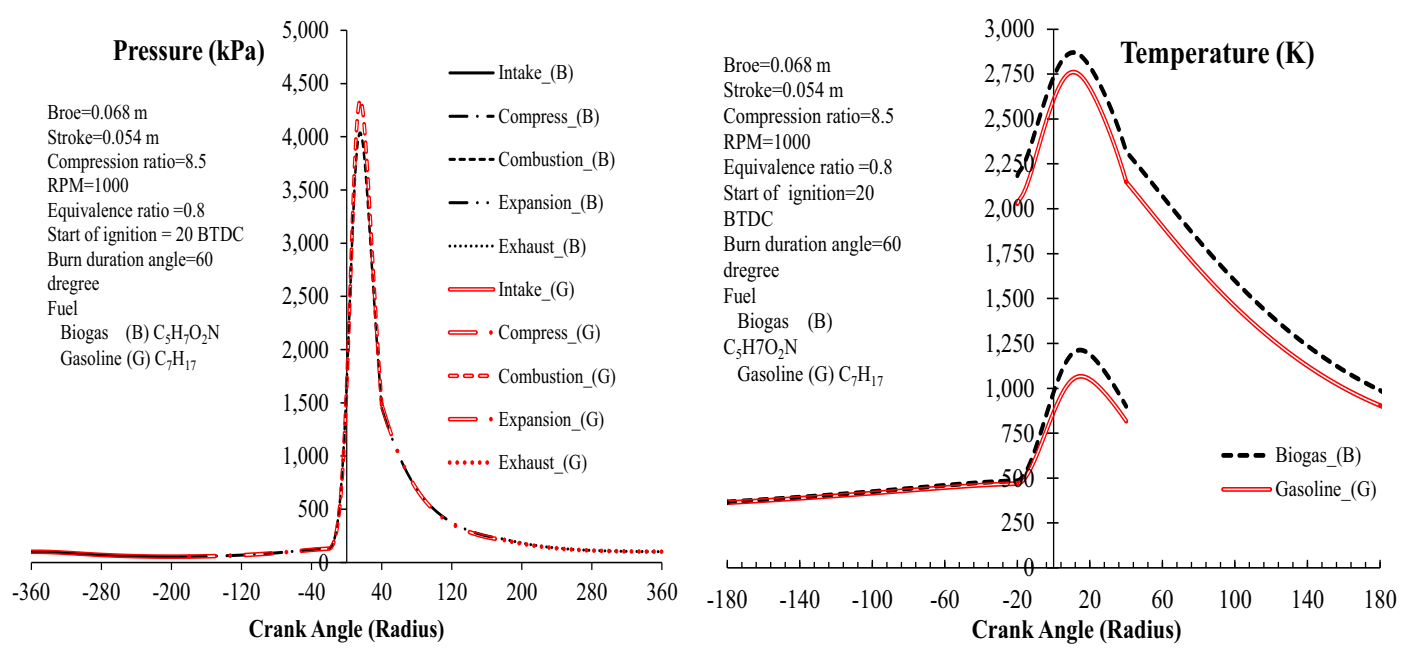

Figure 2. Pressure, Temperature VS Crank angle of all strokes, the engine specifications in Table 1.

Fig. 2, show that the general trend of the pressure results for all strokes agree with the pressure trend of the results with a low heating value of gasoline that have more internal energy more than biogas. So, the agreement of the pressure values depends on the value of energy each fuel. For the engine cycle, the peak pressure is clearly different, only during the combustion stroke. There is a different 
about $300 \mathrm{kPa}(3 \mathrm{bars})$ at $15^{\circ} \mathrm{\theta} \mathrm{BTDC}$, between gasoline and biogas as fuel in the engine. As a result, the pressure is less than this, if the amount is less methane. In general, the case for gasoline as fuel is stable of performance engine because it is a constant value, but biogas is variable property, dependent on the amount of methane and type of reactor. This illustrates the sensitivity of the cylinder pressure to the value of the low heating value or internal energy. The overall gas temperature dependence on crank angle is similar for both the fuel (gasoline and biogas) of the simulation. The peak temperature is $2,700^{\circ} \mathrm{K}$ for gasoline as fuel in combustion stroke of engine and the peak temperature is $2,850^{\circ} \mathrm{K}$ for the case with biogas at $15^{\circ} \theta$ BTDC as the same of pressure. This temperature of gasses in the engine cycle are involved the heat flux was actually determined by making use of the temperature and applying the Newton's law. Consider carefully, the characteristics of the temperature curve for biogas combustion engine is higher than the temperature of gasoline engine as fuel. This is due to the fact that the characteristic of gases properties and equilibrium constant properties for types of reaction in combustion process of biogas fuel are higher and rapidly more than gasoline. This is described in more detail of biogas are low energy and low types of hydrocarbons, but more reaction process than gasoline. This reason can be used to cooling of the engine, while changing fuel.

Results illustrating composition shifts with equivalence ratio are given in Fig. 3 (Biogas, Left) and Fig 3 (Gasoline, Right) in the combustion cylinder chamber of biogas and gasoline at the nearly adiabatic flame temperature $2,000^{\circ} \mathrm{K}$, pressure $4,000 \mathrm{kPa}$, respectively. The results to find, the mole fraction behavior relative to equivalence ratio is complex, the general mole fraction line trends are similar for this result as well. The product types of $\mathrm{CO}$ and $\mathrm{H}_{2}$ generally increase with equivalence ratio are higher, while the $\mathrm{O}_{2}, \mathrm{NO}, \mathrm{OH}$ and $\mathrm{O}$ mole fraction decrease. $\mathrm{But}, \mathrm{CO}_{2}$ and $\mathrm{H}_{2} \mathrm{O}$ of biogas have the clearly differential, while gasoline is similarly value. In additional case of The most significant emission is $\mathrm{NO}_{\mathrm{x}}$ as according internal combustion engine theory, $\mathrm{NO}_{\mathrm{x}}$ emission formation requires many ways such as $\mathrm{O}_{2}, \mathrm{NO}, \mathrm{N}, \mathrm{O}$, high enough temperature, low pressure, the maximum this value is generated when engine runs at stoichiometric $(\mathrm{r}=1)$ as following theory. In simulation of these cases used summation of mole fraction $\mathrm{O}_{2}, \mathrm{NO}, \mathrm{N}$ and $\mathrm{O}$. To found, $\mathrm{NO}_{\mathrm{x}}$ emissions increase with lower combustion of equivalence ratio is lean and decrease with higher combustion of equivalence ratio is rich. The reason be described in more affection of $\mathrm{NO}_{\mathrm{x}}$ is the mole faction of $\mathrm{O}_{2}$, higher specie of $\mathrm{O}_{2}$ is lean side for more reaction (low equivalence ratio) and not enough reaction of $\mathrm{O}_{2}$ at high equivalence ratio. So this model is consistent for the theory in all respects.
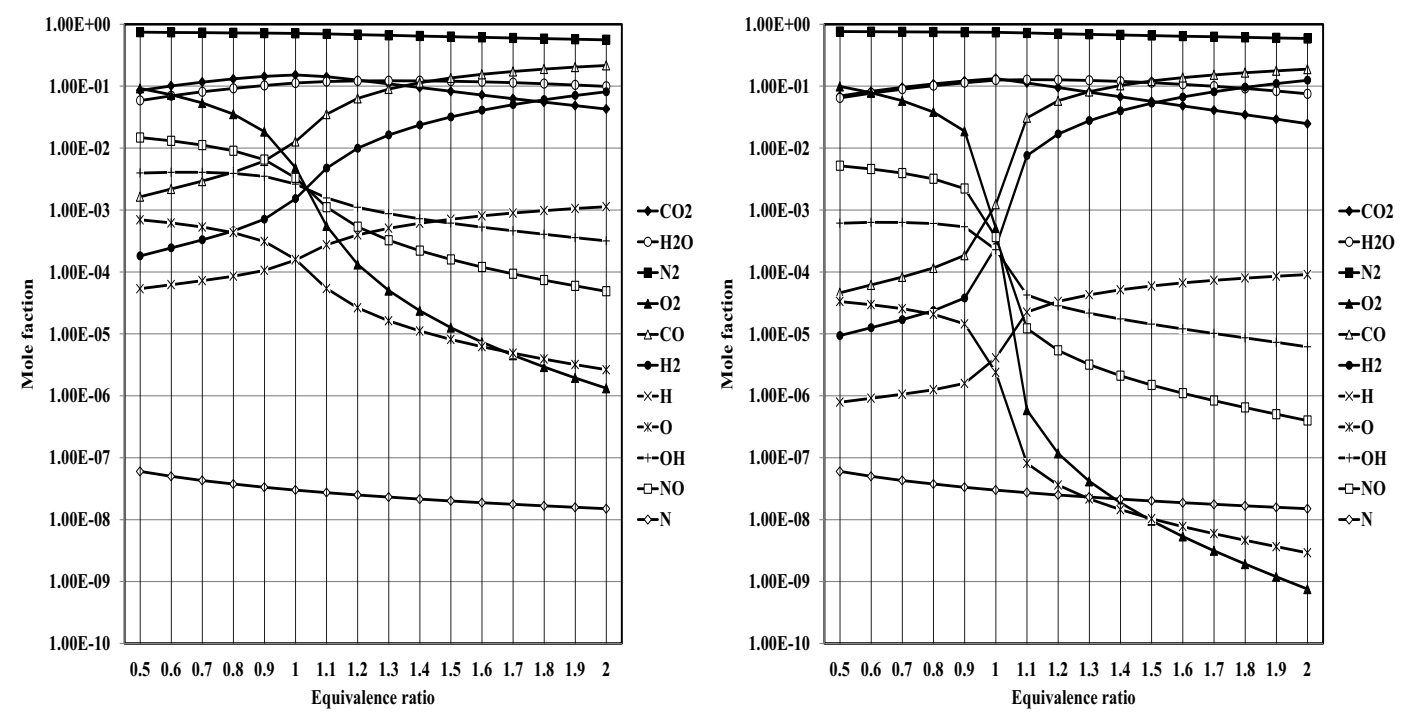

Figure 3. Mole fraction of Biogas (Left) and Gasoline (Right) Combustion with the Equivalence ratio 0.5-2.0 


\section{Conclusion}

Mathematical Modeling program has been used successfully calculate the mole fractions of 11 combustion products when biogas or gasoline (fuel) are burnt along with the spark ignition engine at variable equivalence ratios. It can be observed that hydrogen (biogas, $\mathrm{H}=7$ and gasoline $\mathrm{H}=17$ ) substitution causes significant increase in $\mathrm{H}_{2}$ and $\mathrm{H}$ emissions during rich combustion and $\mathrm{OH}$ and $\mathrm{NO}_{2}$ emissions during lean combustion. As the equivalence ratio increases during rich combustion, mole fractions of $\mathrm{CO}$ and atom $\mathrm{C}$ decreases with increment of hydrogen in fuel substitution. $\mathrm{N}_{2}$, atom $\mathrm{N}$ and $\mathrm{CO}_{2}$ emissions decrease whereas no significant changes in $\mathrm{O}_{2}, \mathrm{NO}$ and atom $\mathrm{O}$ emissions throughout all equivalence ratios as hydrogen is added in fuel to the combustion.

The simulation work achieves its goal of being a simple, fast, accurate engine numerical model for the changing conditions such as equivalence ratio, compression ratio, types of fuel and combustion products. The results obtained can be used as a first-degree approximation and is useful in numerous engineering applications including general design predictions. The numerical model of parameters can predict an array of thermodynamic properties, equilibrium constant as a function of temperature, and non-liner combustion equations and adapt to any mathematical method for solving. It be can used in to study at graduate program of engineering or mathematical sciences. The numerical model of engine parameters can predict an array of thermodynamic term outputs such as pressure, temperature, heat flux, work and easily adapt to any combustion chamber shape or any internal combustion engine. Due to its simplicity and computational efficiency, the model can also be used as a preliminary test for a wide range of alternate hydrocarbon fuels.

\section{Acknowledgment}

This paper was partially financed and given by Department of Mechatronic Engineering, Faculty of Engineering, Rajamangala University of Technology Isan, Khonkaen Campus.

\section{References}

1. T. Sutabutr, Alternative Energy Development Plan: AEDP 2012-2021, International Journal of Renewable Energy, 7, 1 (2012)

2. E. Danso-Boateng, G. Shama a, A.D. Wheatley, S.J. Martin, R.G. Holdich, Hydrothermal carbonisation of sewage sludge: Effect of process conditions on product characteristics and methane production, Bioresource Technology 177, (2015)

3. J. Huang, R.J Crookes, Assessment of simulated biogas as a fuel for the spark ignition engine. Fuel, 77, 15 (1998)

4. W. Sáawomir, Biogas as a fuel for diesel engines, Journal of KONES Powertrain and Transport, 19, 3 (2012)

5. Crookes R.J.: Comparative bio fuel performance in internal combustion engines. Int J Biomass Bioenergy, 30, (2006)

6. D. R. Buttsworth, Spark Ignition Internal Combustion Engine Modeling using Matlab, Faculty of Engineering \& Surveying Technical Reports, University of Southern Queensland, (2002)

7. M. Grill, M. Chiodi, H. Berner, M. Bargende, Calculating the Thermodynamic Properties of Burnt Gas and Vapor Fuel for User-Defined Fuels, MTZ 05-2007 (2007)

8. Colin R. Ferguson, Internal Combustion Engines, Applied Thermosciences. New York: John Wiley and Sons, (1986)

9. Heywood. Joh. B. Internal Combustion Engine Fundamentals. New York McGraw Hill, (1988)

10. J. Paramust, T. Soontornchainacksaen. Calculation of Combustion Products by the New Iteration Method of Non-linear Equations, Journal of Mathematics and System Science, 3, 1 (2013) 